\title{
Adaptation to the disease - the psychological resources of families struggling with multiple sclerosis
}

\begin{abstract}
BACKGROUND
The functioning of a person affected with a chronic illness within a family is a complex and many-sided issue. The illness produces an adaptive mechanism, and the ultimate goal of all adaptive measures is to deal with the new situation. The present research was intended to determine the psychological and clinical factors underlying the correct functioning of families with a multiple sclerosis sufferer.
\end{abstract}

\section{PARTICIPANTS AND PROCEDURE}

The research covered 108 families (216 persons) divided into three groups. We used an interview, the FACES IV questionnaire, the Dyadic Adjustment Scale, the Berlin Social Support Scales, the Coping Inventory for Stressful Situations, the Acceptance of Illness Scale, the Beck Depression Scale, the Mini-Mental State Examination, the Controlled Oral Word Association Test, Raven's Progressive Matrices, and the Similarities task from the Wechsler Adult Intelligence Scale.

\section{RESULTS}

The results of the research showed a significant difference in how family life was assessed by the three groups re- garding cohesion and flexibility. A significant difference also related to communication and family life satisfaction. The best fit with the data was shown by the model incorporating two groups of predictors - global psychological variables (family variables) and individual psychological variables.

\section{CONCLUSIONS}

Based on the research, it is highly probable that the majority of families with multiple sclerosis sufferers adjust relatively well to the disease. Despite chronic illness, a family can function correctly, but this largely depends on its ability to cope with stress. Clinical parameters of the illness, such as the degree of disability, proved to be irrelevant as predictors. It was also established that a system's functioning depends on the mental condition of the healthy care-giving spouse. The patient's cognitive impairment, especially his/her executive deficits, was found to be important.

KEY WORDS

multiple sclerosis; cohesion; family functioning; double $\mathrm{ABC} / \mathrm{X}$ model 


\section{BACKGROUND}

Multiple sclerosis (MS) is a chronic autoimmunological illness of the central nervous system, whose origins have not been fully explained to date. The estimated number of people with MS in the world is approximately 2.3 million (MSIF, 2013). Poland is one of the countries with a high incidence of MS (KapicaTopczewska et al., 2018).

Multiple sclerosis holds a special place among nervous system diseases. The condition is characterized by a complex and relatively diverse clinical course and set of symptoms, as the number and location of demyelination sites vary across individuals. As the disease progresses, it is increasingly accompanied by life-changing neurological, psychiatric and psychological manifestations affecting patients and their families. This is because the family is the human being's primary shelter, a hub of every person's existence. Therefore, the patient's family suffers along with the patient, because - according to the systemic approach - the illness of a system's member is the illness of the entire system.

MS patients and their loved ones struggle against the illness and numerous associated social, employment and financial problems (see De Judicibus \& McCabe, 2007; Green \& Todd, 2008; Grytten \& Maseide, 2006). The illness cuts across life plans, contributing to stress and mental unease. Mood swings, depression, cognitive dysfunction and chronic fatigue syndrome, all of them typical of MS, make it difficult to nurture bonds or stay close as a family (Finlayson \& Cho, 2008; McPheters \& Sandberg, 2010; Treder \& Jodzio, 2014).

Multiple sclerosis considerably affects the quality of a marital relationship (see McPheters \& Sandberg, 2010; Samios, Pakenham, \& O’Brien, 2015; Tompkins, Roeder, Thomas, \& Koch, 2013). Keeping up appropriate marital relations is another challenge, as the illness prevents sufferers from completing daily chores, throwing the relationship off balance (McPheters \& Sandberg, 2010; Rodgers \& Calder, 1990).

The care-taking problem also affects the children of MS sufferers (see Bogosian, Moss-Morris, \& Hadwin, 2010; Pakenham, Bursnall, Chiu, Cannon, \& Okochi, 2006; Treder-Rochna \& Jodzio, 2018; Turpin, Leech, \& Hackenberg, 2008). It is not uncommon to see children parentified, overly burdened or downright stunted in their normal development. This being said, MS affects all family members.

Nonetheless, some researchers are of the opinion that a family member's disease strengthens the family system (Bowen, MacLehose, \& Beaumont, 2011; Pakenham, 2005; Pakenham et al., 2006) in that it fosters tolerance and empathy, while also changing attitudes, especially when it comes to parenthood and child raising. Some patients admit that the disease not only helped them rebuild their lives, but also taught them to take a more reasonable view of it and enjoy the moment (Bowen et al., 2011). Others go so far as to add that being ill made their family relations better (Pakenham, 2005) and improved their marital subsystem (see Ackroyd et al., 2011; Rodgers \& Calder, 1990).

The family seeks new methods to communicate effectively and changes its habits and routines. Generally speaking, illness produces an adaptive mechanism teaching the patient and the people around him to function in a different manner. The gradual progression of MS, on one hand, allows the family to stretch the adaptation process over a period of time, while on the other, those around the sick person find themselves forced to constantly adjust to the patient's current condition and, as a consequence, to subject the family structure to never-ending changes in order to provide care. The ultimate goal of all adaptive measures is to deal with the new situation. Of fundamental importance to the adaptation process is the family's ability to utilize the resources available to them and remedies they have developed in response to the crisis. The double $\mathrm{ABC} / \mathrm{X}$ model seems to be a promising approach that facilitates analysing the process of adaptation to chronic illness (McCubbin, Cauble, \& Patterson, 1982). In that model, resources spring from three sources: personal resources (internal family resources - family potential, the education, personality traits, strategies for coping with stress of the individual family members), systemic resources (internal family resources - cohesion, emotional bonds, marital quality), social resources (external resources - other people). The marital dyad is particularly vital to family life (McPheters \& Sandberg, 2010; Rodgers \& Calder, 1990). McCubbin et al. (1982) believe that stress-coping skills bear most of the weight of the adaptation process. Social support plays an important role (McPheters \& Sandberg, 2010). Clinical variables related to the course of illness also play a role. A literature review identified cognitive dysfunctions, increase in depression (Figved, Myhr, Larsen, \& Aarsland, 2007; Finlayson \& Cho, 2008) and the degree of disability in the patient (van Asch, 2011) as key factors for families.

The present-day literature argues that persons with MS and their families develop interpersonal, sociopsychological, and even psychiatric problems. With deteriorating marital relations, it becomes difficult to maintain strong emotional bonds with children. As a result, the entire family becomes increasingly isolated socially and thereby stigmatized. Nevertheless, some families deal successfully with the predicament induced by the disease by taking satisfaction in caring for the patient. It is a key requirement, however, to offer support to all families, both those going through temporary difficulties and those in need of immediate therapy. At the same time, it is advisable that psychological assistance be preceded by a physical and functional diagnosis of the patients themselves and their families to allow determination of which variables
The psychological resources of families struggling with multiple sclerosis 
facilitate the particular family's coping with illness The overriding general aim of this study is to specify the psychological and clinical determinants of soundly functioning MS families. The nature of that goal is strictly practical, for there is little research on the factors that determine the correct functioning of a family with a chronically ill person. The majority of reports focus on families that do not cope well with difficult situations. The problem needs exploring in order that a determination can be made of those psychological and clinical variables which benefit MS families, thereby aiding in therapeutic work and in seeking out the strong points of and promoting healthy families.

\section{PARTICIPANTS AND PROCEDURE}

\section{PARTICIPANTS}

One hundred and eight families (216 persons - wives and husbands), aged from 40 to $64(S D=4.46)$, participated in the study. They were divided into three groups: the clinical group (multiple sclerosis group, MSG), control group no. 1 (healthy group, CI) and control group no. 2 (paraplegia group, CII). The clinical group (43 families, 86 person) consisted of families with a MS sufferer. The first control group (35 families, 70 person) comprised family systems free from chronic diseases, while the second control group (30 families, 60 person) was composed of families with one of the spouses suffering from spinal cord injury having the clinical form of paraplegia. No statistically significant differences were noted between the groups as to age $(F(2,213)=1.47, p=.232$, $\left.\eta^{2}=.12\right)$, number of years in marriage $(F(2,213)=1.74$, $\left.p=.171, \eta^{2}=.13\right)$ or number of years of school education $\left(F(2,213)=2.03, p=.131, \eta^{2}=.14\right)$. However, differences were observed in the distribution of the gender factor across the sufferers in the clinical and second control groups $\left(\chi^{2}(1, N=73)=7.06, p<.01\right)$. Specifically, the incidence of MS was higher for women in the MSG and for men in CII. The differences arise from the nature of the disease. Multiple sclerosis affects mainly women. At the same time, $80-85 \%$ of spinal cord injuries are encountered in males (Kiwerski, Kowalski, \& Krasuski, 1997).

A total of 43 MS patients were examined (58\% women and $42 \%$ men). The average time-span of the disease was 20.04 years $(S D=8.41)$. The relapsingremitting variant of the disease predominated (48\%). Most of the patients required aid to move (a cane, crutch or walking frame).

\section{RESEARCH METHODS}

A set of standardized psychological tests was selected to operationalize the variables (Table 1). The variables and methods were chosen to reflect the overarching research goal of searching for variables with a decisive impact on healthy family functioning. Based on the double $\mathrm{ABC} / \mathrm{X}$ model and literature review, diverse methods were selected to identify family functioning, the quality of marital life, support level and stress management skills. The results indicated that a certain influence on family functioning was also exercised by clinical variables related to the course of illness. However, cognitive dysfunctions and increase in de-

Table 1

Variables and research methods

\begin{tabular}{ll}
\hline Variables & \multicolumn{1}{c}{ Methods } \\
\hline Demographic data and medical information & Clinical interview, analysis of medical records \\
Family functioning & The FACES IV questionnaire \\
Quality of marital life & The Dyadic Adjustment Scale (DAS) \\
Social support & Berlin Social Support Scales (BSSS) \\
Coping styles for stress & Coping Inventory for Stressful Situations (CISS) \\
Depression & Beck Depression Scale (BDI) \\
Acceptance of illness & Acceptance of Illness Scale (AIS) \\
Cognitive functions & Mini-Mental State Examination (MMSE) \\
& Controlled Oral Word Association Test (COWAT) \\
& Raven's Progressive Matrices (RPM) \\
& Similarities task from Wechsler Adult Intelligence \\
\end{tabular}

Note. FACES IV questionnaire, DAS, BSSS, CISS, BDI scale surveys were taken by all study subjects. The AIS questionnaires and tests used to assess cognitive functioning were given only to MS sufferers. However, in keeping with the overarching research goal, differences between mean scores between the studied groups within the scales of each questionnaire were not discussed. 
pression in the patient have primary importance. The research also considered illness acceptance, as that variable also has implications for the adaptive process.

The FACES IV questionnaire based on the Circumplex Model by Olson (2011) - a Polish adaptation (Margasiński, 2013) was the main family assessment instrument. The questionnaire consists of 62 items grouped into 8 principal scales: Balanced Cohesion, Balanced Flexibility, Disengagement, Enmeshment, Rigidity, Chaos, Family Communication Scale, and Family Satisfaction Scale. A general assessment of the way in which a family functions can be made by dividing the average of scores obtained on the Balance Scales by the average of scores obtained on the Imbalance Scales. The higher the end result, the closer the examined family system is to being balanced, or "healthy" (Margasiński, 2013).

The Dyadic Adjustment Scale (DAS) developed by Spanier - a Polish adaptation (Cieślak, 1989) was used to assess the quality of marriage. The scale includes four aspects of marital adaptation: Dyadic Consensus, Dyadic Cohesion, Dyadic Satisfaction, and Affectional Expression.

The Berlin Social Support Scales (BSSS) by Schwarzer and Schulz - a Polish adaptation (Łuszczyńska, Kowalska, Mazurkiewicz, \& Schwarzer, 2006) was used to assess social support. The BSSS consists of 5 independent scales: Perceived Available Support (emotional, instrumental), Need for Support, Support Seeking, Actually Received Support, and Protective Buffering Support.

The popular CISS scale (Coping Inventory for Stressful Situations) authored by Endler and Parker - a Polish adaptation (Strelau, Jaworowska, Wrześniewski, \& Szczepaniak, 2005) was used to examine the way in which an individual typically behaves under stress, or the coping styles for stress. The scale comprises three styles of coping with stress: TaskOriented Coping (TOC), Emotion-Oriented Coping (EOC), and Avoidance-Oriented Coping (AOC).

The widely used Beck Depression Scale (BDI) was used to assess depression (Czapiński, 1992).

The Acceptance of Illness Scale (AIS), developed by Felton and Revenson - a Polish adaptation (Juczyński, 2009) was used to examine the acceptance of illness.

A general cognitive assessment was carried out to evaluate reasoning by analogy, abstract reasoning, verbal and executive functions. There was an effort to seek variables with a possible impact on family functioning and communication within the family. In choosing the research tools, priority was given to short-term methods with satisfactory psychometric properties. MS sufferers are a special patient group frequently struggling with chronic fatigue, which makes any test of long duration difficult or impossible.

Selected cognitive functions were evaluated with four diagnostic tests widely used in the neuropsychological community:
- Mini-Mental State Examination (MMSE);

- Controlled Oral Word Association Test (COWAT);

- Raven's Progressive Matrices (RPM);

- Similarities task from Wechsler Adult Intelligence Scale - WAIS-R(PL).

\section{RESEARCH PROCEDURE}

All assessments were carried out by the author. Participants from all groups were examined individually. Clinical interview with the sufferer and his/her spouse was the research tool. The sessions lasted about 90 minutes. Before being included in the research all MS patients had been assessed with the Mini-Mental State Examination and Beck Depression Inventory. All patients with an MMSE score lower than 20 or displaying signs of major depression (BDI above 27 points) were excluded from the research. Prior to the study, written informed consent was obtained from all participants.

The investigation targeted full families having at least one child. A considerable portion of the families were in the fifth stage of the family life cycle when children leave the family home, with the mother and father being tasked to help them navigate through life choices and achieve independence. The stage within the family life cycle was determined based on an interview, as dictated by the model proposed by Duvall (1977)

The protocol was approved by the Ethics Board for Research Projects at the Institute of Psychology, University of Gdansk, Poland. After completing the research, the participants were told about the aim of the study, thanked, and fully debriefed.

\section{RESULTS}

The first stage of statistical analysis focused on intergroup differences in the functioning of the family (as perceived by the spouses). An arithmetic mean was calculated out of the scores gained by both the spouses on the individual scales in the FACES IV questionnaire. The analyses utilised a one-way betweengroups ANOVA and a post hoc Tukey test for comparison purposes. The dependent variables were averaged scores obtained by the spouses on the individual scales in the FACES IV questionnaire. Independent variables were defined as group membership (MSG $\times \mathrm{CI} \times \mathrm{CII})$. A detailed presentation of the results is included in the previous article (see Treder-Rochna \& Jodzio, 2018).

There are two levels of family balance - balanced cohesion and balanced flexibility (the higher the score on the scales, the better the system will function). A statistically significant difference was observed on the Balanced Cohesion $(F(2,105)=11.99, p<.001$, $\left.\eta^{2}=.34\right)$ and Balanced Flexibility scale $(F(2,105)=6.74$,
The psychological resources of families struggling with multiple sclerosis 
$\left.p<.01, \eta^{2}=.35\right)$. Families with a person suffering from MS (multiple sclerosis group, MSG), and families with a paraplegic (paraplegia group, CII) scored significantly lower on the Balanced Cohesion scale as compared with families free from a chronic illness (healthy group, CI). However, in the case of balanced flexibility, a slightly different pattern was observed the families in the paraplegia group scored lower than families in the healthy group, but no inter-group differences were observed between MSG, on one hand, and $\mathrm{CI}$ and CII, on the other.

There are four imbalance scales - Disengagement, Enmeshment, Rigidity, and Chaos (the higher the score on the scales, the worse the functioning of the family system). Two cohesion levels - low (disengaged systems) and high (enmeshed systems), and two flexibility levels - low (rigid systems) and high (chaotic systems), are present. A statistically significant difference between the groups related to the intensity level of cohesion: disengagement $(F(2,105)=11.37$, $\left.p<.001, \eta^{2}=.46\right)$ and enmeshment $(F(2,105)=4.76$, $\left.p<.01, \eta^{2}=.29\right)$. As compared with CI families, MSG families scored considerably higher on the Enmeshment Scale. No inter-group differences were observed between the CI and CII groups. A statistically significant difference between the groups related to the intensity level of flexibility: rigidity $(F(2,105)=13.61$, $\left.p<.001, \eta^{2}=.46\right)$, and chaos $(F(2,105)=4.55, p<.05$, $\left.\eta^{2}=.24\right)$. Compared with CI families, MSG families scored considerably higher on the Rigidity scale. In terms of chaos, families with a paraplegic scored significantly higher than families with an MS sufferer and families free from chronic diseases.

Also, families with an MS sufferer also scored higher than CII families on communication $\left(F(2,105)=3.38, p<.05, \eta^{2}=.28\right)$ and family life satisfaction $\left(F(2,105)=3.14, p<.05, \eta^{2}=.23\right)$.

The next step in the investigation was an attempt to identify psychological and clinical variables rele- vant to the way in which MS families function. Multiple regression analysis was calculated. An analysis of hierarchical regression was carried out, with the general index of MS family health as the response variable. Three variable types, i.e. global psychological variables (family variables), individual psychological variables and clinical variables, were entered into the regression eIn the first step, the global psychological variables (family variables) were entered, as the spouses' general score on Spanier's DAS scale, the spouses' total score on each of the CISS scales, and the spouses' total score for the perceived available support sub-scale in the BSSS questionnaire. Due to its systemic nature, the research adopted mean scores gained by both the spouses, incorporating an overall picture of the marital relationship, the family's prevalent style of coping with stress and perceived family support.

In the second step, the individual variables were entered, i.e. the patient's scores in neuropsychological tests (Verbal Fluency Test, Similarity Sub-Test with WAIS-R, and Raven Progressive Matrices, version A and B), scores on the AIS and BDI scales, and the spouse's score on the BDI scale. The individual variables included those that describe the patient's and his/her spouse's mental condition, and the AIS score for the patient only. This is because illness acceptance can only be measured in the patient himself/herself as a determinant of his/her adaptive attitude to the disease. In the third step, clinical variables were entered, including the diseased person's gender, form of MS, and motor ability.

The best fit with the data $\left(R^{2}=.83, F(1,43)=10.77\right.$, $p<.001)$ was shown by the model incorporating two groups of predictors (global psychological variables and individual psychological variables). The model with predictor groups accounts for $83 \%$ of variance in the dependent variable. The variables that were entered into the regression equation are listed in Table 2.

Table 2

Results of regression analysis for functioning of the family

\begin{tabular}{lcccc}
\hline & Variables & $\beta$ & $t$ & $p$ \\
\hline Family functioning with & DAS (general score) & .25 & 2.34 & .059 \\
multiple sclerosis patients & AOC (general score) & -.42 & -3.17 & .021 \\
& SD (general score) & .15 & 2.64 & .033 \\
& BDI (spouse) & -.66 & -4.32 & .002 \\
COWAT FF (TW) & .43 & 4.83 & .003 \\
& COWAT FF (SW) & .42 & 3.47 & .019 \\
\hline
\end{tabular}

Note. DAS - Dyadic Adjustment Scale; AOC - Avoidance-Oriented Coping; SD - Social Diversion; BDI - Beck Depression Inventory; COWAT - Controlled Oral Word Association Test; FF - Phonological Fluency; FS - Semantic Fluency; TW - Total Words Produced; SW - Switches. 
A strong negative relationship was found between the MS spouse's subjective depression level and the dependent variable $(\beta=-.66, p=.002)$.

Predictors that explain the dependent variable include AOC results $(\beta=-.42, p=.021)$, MS patient's scores in the Verbal Fluency Test (total words produced for phonological fluency) $(\beta=.43, p=.003)$, the number of between-cluster phonological switches ( $\beta=.42, p=.019)$ and the number of between-cluster semantic switches $(\beta=.43, p=.016)$.

\section{DISCUSSION}

The functioning of a family with a chronically ill person is among the vital psychological problems. The family members of an MS sufferer appear to be in a particularly difficult situation. It is also worth mentioning that MS holds a special place among neurological conditions. It is a chronic and incurable illness which may be possibly accompanied by psychiatric and psychological symptoms. A lack of effective treatment methods, insecurity about the future, and fear of death, or being misunderstood by society, are just a few of the problems faced by the sufferers and their families.

The results obtained produced data throwing light on selected aspects of the functioning of families with an MS sufferer, going through the fifth phase of their lifecycle. In terms of cohesion, the family structure was found to be different in different examined groups. In the most general sense, systems struggling with a disease exhibit emotional difficulties stemming from various causes. In the case of families taking care of an MS patient, these difficulties related primarily to excessive cohesion, as opposed to families with a paraplegic characterized mainly by insufficient cohesion. Family systems featuring an MS sufferer are characterized by a strong emotional bond, and excessive identification with and loyalty to the family members. Time spent together and joint decision-making are prominent, but individual space is severely limited, leading to a lack of autonomy and individualization in the family members. An exaggerated family focus seems disadvantageous for the MS sufferer's children (see Treder-Rochna \& Jodzio, 2018).

As determined, MS families are systems with varying degrees of flexibility. The results are consistent with data from other authors (Bowen et al., 2011; Ochojska, 2000). Most of these MS families are generally capable of adjusting to structural and functional changes under difficult circumstances. However, cases are known of overly rigid families. The opposite is true of families with a paraplegic, which were found to be overly chaotic. Families of this type lack governance, discipline or clear rules.

Also, MS families usually reported satisfaction with family life and an ability to communicate ef- fectively. This was not the case with families with a paraplegic, where reported family life satisfaction and communication were far inferior.

The research conducted suggests that the majority of families struggling with MS adapt relatively well to the disease. Participants were satisfied with their family life, which provides further evidence for their correct adaptation to the disease. It should be pointed out that the majority of the surveyed families taking care of MS sufferers were characterized by excessive cohesion. It is certainly true that strong emotional bonds present in families with an MS sufferer put these families at an advantage. An atmosphere of closeness provides a sense of security, readiness to give help, but may also make it difficult or impossible for the other family members to develop their individuality and autonomy (see Treder-Rochna $\&$ Jodzio, 2018). Based on the research, it can be supposed that the majority of MS families have developed an adaptive mechanism that benefits the patient. In examining the problems related to the functioning of families struggling with a chronic illness, it should be remembered, as pointed out by Anne M. Meijer and Louis Oppenheimer (the creators of the excitation-adaptation model, 1995), that what is untypical and out of order in systems free from disease may be typical, or even beneficial, in families with a sick person. An elevated level of cohesion may be seen as "a positive adaptive mechanism" which should come as a natural systemic response to a crisis in the form of illness. Therefore, it is a good idea to look at families that cope successfully with illness and reflect on what it is that determines their success.

The practical aim of this study was to identify the variables contributing to the correct functioning of a family despite MS. Stress coping styles were found to have relevance in this context. In a soundly functioning system the avoidant style of attachment is hardly ever to be seen, because a passive approach to problems lessens the sense of responsibility and discourages any initiatives due to a feeling of lack of control over the events. At the same time, an avoidant style of coping with stress proves to be ineffective and disadvantageous to functioning as a family with a terminally ill member.

What favours sound functioning as a family is coping with stress through seeking contact with other people. This strong need is evidenced by the fact that $87 \%$ of the affected families reported membership in a multiple sclerosis association. Participants emphasized that meeting other sufferers helped them accept their own situation, change their lifestyle and cope better with difficulties. Only a few of them felt disappointed with their families' and friends' attitude. This was the case especially with patients confined to a wheelchair, who stated that their disability had restricted their relations with other people.
The psychological resources of families struggling with multiple sclerosis 
The disease had encouraged the families to open up. Here, one of the basic adaptive mechanisms under difficult conditions, i.e. opening up to contact with other people, had been activated. It should be stressed at this point that families with a sense of stability and family members sharing a close bond with each other are more likely to seek help from strangers, for they do not fear the destruction of the system. Also, research shows that MS sufferers who feel strongly supported by their loved ones evaluate their own state of health higher, and present with less intense depressive symptoms and better self-esteem than patients who lack such aid. Family support has a beneficial effect on the diseased person's quality of life (Krokavcova et al., 2008), while failure to receive support reduces it dramatically while also contributing to depression (Chwastiak et al., 2002; McPheters \& Sandberg, 2010).

It has also been shown that the mental state of the spouse not suffering from MS is of crucial importance for the correct functioning of the family. The system operates less well when the caregiver's mood is low. Similar findings were reported by McPheters and Sandberg (2010), whereby a depressed caregiver may significantly lower the quality of marital relations and worsen the entire family's ability to cope with the illness. It is quite likely that symptoms of depression in the non-affected spouse come as a response to the need for constant care-giving in the face of progressing disability. It is also possible that the partner does not cope well with the situation of illness, contributing to an overall slump in the entire family system's performance. It is noteworthy that, according to research, the risk of marital problems is made more acute by the patient's progressive disability (see McPheters \& Sandberg, 2010; Rodgers \& Calder, 1990). This is believed to link back to the healthy spouse's being overwhelmed with work, with the weakening spousal bonds favouring the onset of depression in the previously healthy spouse (McPheters \& Sandberg, 2010). On the other hand, my own research shows that neither the clinical side of the illness as such nor the degree of disability had any crucial impact on the functioning of the family. Also, the level of depression in the sick person and his/her acceptance of the illness do not seem to be reliable predictors of how the family will function.

What turns out to have relevance to the functioning of the family is the sufferer's cognitive impairment, especially where this relates to his/her generation of semantic content, mental flexibility and multitasking. This is because patients seem to find it very difficult to search through different kinds of information and switch between different categories of these. Switching capability, or the ability to fluently switch one's mental attitude from word to word, requires mental flexibility and multitasking, which are connected with executive functions and oper- ating memory (Lezak, Howieson, Loring, Hannay, \& Fischer, 2004). A switching deficit seems to correlate with frontal and subcortical lesions (Lezak et al., 2004), as indicated by the executive dysfunctions found in the patients. These dysfunctions make everyday life difficult, especially where a need to execute complex actions arises, leading to family problems. It is a good idea at this point to refer to research by Rao et al. (1991). The research examined the relationship between cognitive dysfunctions and social life of MS sufferers. The researchers singled out a subgroup of cognitively dysfunctional and a subgroup of cognitively non-dysfunctional patients, but the groups did not differ in terms of degree of motor disability or duration of illness. The cognitively dysfunctional patients were less willing to engage in career work and reported more problems in social, professional and sexual life. For them, daily activities were a source of stress and discomfort. Generally speaking, cognitive impairment determines to a large extent the quality of life for the patient and his/her family.

Research suggests that the majority of the studied families with an MS patient adapt relatively well to the diseases, while also developing an adaptive mechanism which psychologically benefits the patient. This does not mean, however, that such families are free from problems.

I hope that the results of this research will serve to develop a therapy programme for families struggling with MS. Important psychological resources to be used in working with patients and their families include effective strategies for coping with stress and the ability to seek out and accept social support. Therapeutic efforts should aim to eliminate avoidant forms of coping with stress and develop the capability to seek assistance from outside. It is vital to help the patients and their loved ones to find active ways to combat illness. Support groups are an important addition to professional counselling. It is important to encourage the whole family to actively participate in support group meetings. Psychological assistance should cover both the patient and his family members. Families with a sick person need therapeutic help and education at various stages of the family life cycle. Some require intensive therapy, while others only need to be educated and helped periodically in difficult situations to restore normalcy and maximize their own potential.

Support for healthy spouses is also key. It seems necessary therefore to incorporate various forms of counselling for couples and also individual therapy for spouses into the general treatment programme for MS. Special care should be extended to the children of MS sufferers. The psychosocial problems of children of people with MS have been discussed in a separate paper (see Treder-Rochna \& Jodzio, 2018).

In this way, it is possible to prevent many difficulties - or at least diminish their destructive influence 
- by working to avoid a profound dysfunctionality. It would be particularly valuable to conduct longitudinal research to investigate the dynamics of change in the way the family functions in different phases of its life cycle. It is not impossible that different variables are relevant to the system's proper functioning at different stages. Further research is also required in the field of families with a paraplegic, which this article only hinted at. Those affected reported severe and numerous psychological and social problems, even in comparison with the families of MS sufferers.

\section{CONCLUSIONS}

As predicted, the presence of MS in the family was found to impact its functioning. Family systems featuring MS sufferers were characterized by excessive cohesion. At the same time, a majority of them were good at dealing with change. The correct functioning of a family, despite chronic illness, depends on its ability to cope with stress, the care-giving spouse's mental condition and the patient's cognitive impairment. Clinical variables related to the illness and disability degree turned out to have little or no relevance.

The problem of how a family affected by MS functions requires further research. The results of such research will be important for theoretical (determining traits specific to such families) and practical (establishing a complete model for the functioning of a family with an MS sufferer) purposes.

A detailed and person-oriented exploration of the situation of sufferers will provide an opportunity to offer better assistance while also mitigating the consequences of the illness.

\section{ACKNOWLEDGMENTS}

I would like to thank all of the patients, collaborators, and institutions which helped make this study possible. I would also like to thank Prof. Jodzio for his support and providing critical revisions of the manuscript.

\section{REFERENCES}

Ackroyd, K., Fortune, D. G., Price, S., Howell, S., Sharrack, B., \& Isaac, C. L. (2011). Adversarial growth in patients with multiple sclerosis and their partners: Relationships with illness perceptions, disability and distress. Journal of Clinical Psychology in Medical Settings, 18, 372-379. https://doi. org/10.1007/s 10880-011-9265-0

Bogosian, A., Moss-Morris, R., \& Hadwin, J. (2010). Psychosocial adjustment in children and adoles- cents with a parent with multiple sclerosis: a systematic review. Clinical Rehabilitation, 24, 789801. http://doi: 10.1177/0269215510367982

Bowen, C., MacLehose, A., \& Beaumont, J. G. (2011). Advanced multiple sclerosis and the psychosocial impact on families. Psychology and Health, 26, 113127. https://doi.org/10.1080/08870440903287934

Chwastiak, L., Ehde, D. M., Gibbons, L. E., Sullivan, M., Bowen, J. D., \& Kraft, G. H. (2002). Depressive symptoms and severity of illness in multiple sclerosis: Epidemiologic study of a large community sample. American Journal of Psychiatry, 159, 18621868. https://doi.org/10.1176/appi.ajp.159.11.1862

Cieślak, K. (1989). Polska wersja skali G. B. Spaniera służącej do pomiaru jakości związku małżeńskiego (DAS) [The Polish version of the Dyadic Adjustment Scale]. Przeglad Psychologiczny, 32, 1041-1049.

Czapiński, J. (1992). Psychologia szczęścia [Psychology of happiness]. Warszawa: Akademos.

De Judicibus, M. A., \& McCabe, M. P. (2007). The impact of the financial costs of multiple sclerosis on quality of life. International Journal of Behavioral Medicine, 14, 3-11. https://doi.org/10.1007/BF02999222

Duvall, E. M. (1977). Marriage and family development (5 ${ }^{\text {th }}$ ed.). Philadelphia, PA: Lippincott.

Figved, N., Myhr, K. M., Larsen, J. P., \& Aarsland, D. (2007). Caregiver burden in multiple sclerosis: The impact of neuropsychiatric symptoms. Journal of Neurology, Neurosurgery and Psychiatry, 78, 10971102. https://doi.org/10.1136/jnnp.2006.104216

Finlayson, M., \& Cho, C. (2008). A descriptive profile of caregivers of older adults with MS and the assistance they provide. Disability and Rehabilitation, 30, 1848-1857. https://doi.org/10.1080/096382807017 07324

Green, G., \& Todd, J. (2008). "Restricting choices and limiting independence": Social and economic impact of multiple sclerosis upon households by level of disability. Chronic Illness, 4, 160-172. https:// doi.org/10.1177/1742395307087457

Grytten, N., \& Måseide, P. (2006). "When I am together with them I feel more ill." The stigma of multiple sclerosis experienced in social relationships. Chronic Illness, 2, 195-208. https://doi. org/10.1179/174592006X129482

Juczyński, Z. (2009). Narzędzia pomiaru w promocji i psychologii zdrowia [NPPPZ. Assessment and diagnostic instruments for health psychology promotion]. Warszawa: Pracownia Testów Psychologicznych Polskiego Towarzystwa Psychologicznego.

Kapica-Topczewska, K., Brola, W., Fudala, M., Tarasiuk, J., Chorazy, M., Snarska, K., Kochanowicz, J., \& Kulakowska, A. (2018). Prevalence of multiple sclerosis in Poland. Multiple Sclerosis and Related Disorders, 21, 51-55. http://doi: 10.1016/j.msard.2018.02.016

Kiwerski, J., Kowalski, M., \& Krasuski, M. (1997). Schorzenia i urazy kręgostupa [Diseases and spinal injuries]. Warszawa: Wydawnictwo Lekarskie PZWL.
The psychological resources of families struggling with multiple sclerosis 
Krokavcova, M., van Dijk, J. P., Nagyova, I., Rosenberger, J., Gavelova, M., Middel, B., Gdovinova, Z. \& Groothoff, J.W. (2008). Social support as a predictor of perceived health status in patients with multiple sclerosis. Patient Education and Counseling, 73, 159-165. https://doi.org/10.1016/j.pec.2008.03.019

Lezak, M. D., Howieson, D. B., Loring, D. W., Hannay, H. J., \& Fischer, J. S. (2004). Neuropsychological assessment. New York: Oxford University Press.

Łuszczyńska, A., Kowalska, M., Mazurkiewicz, M., \& Schwarzer, R. (2006). Berlińskie Skale Wsparcia Społecznego (BSSS). Wyniki wstępnych badań nad adaptacją skal i ich własnościami psychometrycznymi [Berlin Social Support Scales (BSSS): Polish version of BSSS and preliminary results on its psychometric properties]. Studia Psychologiczne, 44, 17-27.

Margasiński, A. (2013). Skale Oceny Rodziny. Polska adaptacja FACES IV (Flexibility and Cohesion Evaluation Scales) Davida H. Olsona [Polish adaptation of FACES IV (Flexibility and Cohesion Evaluation Scales) by David H. Olson]. Warszawa: Pracownia Testów Psychologicznych Polskiego Towarzystwa Psychologicznego.

McCubbin, H. I., Cauble, A. E., \& Patterson, J. M. (1982). Family stress, coping, and social support. Springfield, IL: Charles Thomas Publisher Ltd.

McPheters, J. K., \& Sandberg, J. G. (2010). The relationship among couple relationship quality, physical functioning, and depression in multiple sclerosis patients and partners. Families, Systems and Health, 28, 48-68. https://doi.org/10.1037/a0018818

Meijer, A. M., \& Oppenheimer, L. (1995). The excitation-adaptation model of pediatric chronic illness. Family Process, 34, 441-454. https://doi. org/10.1111/j.1545-5300.1995.00441.x

MSIF (2013). Atlas of MS 2013. Multiple Sclerosis International Federation. Retrieved from http:// www.msif.org/wp-content/uploads/2014/09/Atlasof-MS.pdf

Ochojska, D. (2000). Stwardnienie rozsiane i rodzina: psychologiczna analiza sytuacji w rodzinach osób dorostych chorych na stwardnienie rozsiane [Multiple sclerosis and the family: Psychological analysis of the situation in which families of adults suffer from multiple sclerosis]. Rzeszów: Wydawnictwo Wyższej Szkoły Pedagogicznej.

Olson, D. H. (2011). FACES IV and the Circumplex Model: validation study. Journal of Marital and Family Therapy, 37, 64-80. http://doi: 10.1111/j.17520606.2009.00175.x

Pakenham, K. I. (2005). Benefit finding in multiple sclerosis and associations with positive and negative outcomes. Health Psychology, 24, 123-132. https://doi.org/10.1037/0278-6133.24.2.123

Pakenham, K. I., Bursnall, S., Chiu, J., Cannon, T., \& Okochi, M. (2006). The psychosocial impact of caregiving on young people who have a parent with an illness or disability: Comparisons between young caregivers and noncaregivers. Rehabilitation Psychology, 51, 113-126. https://doi.org/ 10.1037/0090-5550.51.2.113

Rao, S. M., Leo, G. J., Ellington, L., Nauertz, T., Bernardin, L., \& Unverzagt, F. (1991). Cognitive dysfunction in multiple sclerosis. II. Impact on employment and social functioning. Neurology, 41, 692-696. https://doi.org/10.1212/WNL.41.5.692

Rodgers, J., \& Calder, P. (1990). Marital adjustment: a valuable resource for the emotional health of individuals with multiple sclerosis. Rehabilitation Counseling Bulletin, 34, 24-32.

Samios, C., Pakenham, K. I., \& O’Brien, J. (2015). A dyadic and longitudinal investigation of adjustment in couples coping with multiple sclerosis. Annals of Behavioral Medicine, 49, 74-83. https:// doi.org/10.1007/s12160-014-9633-8

Strelau, J., Jaworowska, A., Wrześniewski, K., \& Szczepaniak, P. (2005). Kwestionariusz radzenia sobie w sytuacji stresowej CISS. Podręcznik [CISS. Coping Inventory for Stressful Situations]. Warszawa: Pracownia Testów Psychologicznych Polskiego Towarzystwa Psychologicznego.

Tompkins, S. A., Roeder, J. A., Thomas, J. J., \& Koch, K. K. (2013). Effectiveness of a relationship enrichment program for couples living with multiple sclerosis. International Journal of MS Care, 15, 27-34. https:// doi.org/10.7224/1537-2073.2012-002

Treder, N., \& Jodzio, K. (2014). Prevalence and clinical specificity of fatigue symptoms in chronic fatigue syndrome, multiple sclerosis, and myasthenia gravis. Health Psychology Report, 2, 83-89. https:// doi.org/10.5114/hpr.2014.43914

Treder-Rochna, N., \& Jodzio, K. (2018). Specyfika funkcjonowania rodzin osób chorych na stwardnienie rozsiane w Modelu Kołowym Olsona [The specificity of functioning of the multiple sclerosis patient's families in the Olson Circumplex Model]. Psychologia Rozwojowa, 23, 55-64. https://doi.org/10.4467/20 843879pr.18.016.9357

Turpin, M., Leech, C., \& Hackenberg, L. (2008). Living with parental multiple sclerosis: Children's experiences and clinical implications. Canadian Journal of Occupational Therapy, 75, 149-156. https:// doi.org/10.1177/000841740807500306

van Asch, P. (2011). Impact of mobility impairment in multiple sclerosis 2-patients' perspectives. European Neurological Review, 6, 115-120. https://doi. org/10.17925/enr.2011.06.02.115 